13. Holden, Ward.-Transactions American Ophthalmological Society, 1898, Reference in Ophthalmic Review, 1899.

14. Barabaschew.-Vestnik Ophtal., Reference in Oththalmic Review, Vol. X, I89I.

I5. Stasinski, J. - Klin. Monatshl. für Augenheilkunde, Vol. XLVII, I9IO.

16. Zanotti, M.-Reference in Ophthalmic Review, Vol. XVIII, I899.

17. Fortunati.-Reference in Centralblatt f. prakt. Augenheilkunde, Vol. XXIX, 1905 .

\title{
THE INFLUENCE OF VASCULAR DISEASE IN THE RETINA ON THE PROGNOSIS AS REGARDS LIFE.*
}

BY

\author{
P. H. ADAMS, F.R.C.S., D.O.,
}

MARGARET OGILVIE READER IN OPHTHALMOLOGY, UNIVERSITY OF OXFORD.

THE most numerous cases of general medical interest that we, as ophthalmic surgeons, see are those that have some form or other of disease of the vascular system. It is by no means unusual for the failure of vision to be the first symptom that obtrudes itself on the notice of the patient, and sends him to seek advice of the eye specialist. These cases one examines and finds various pathological manifestations in the retina, returns them to their general medical adviser for treatment, and not infrequently loses sight of them henceforth, or else they attend the hospital, are put on to potassium iodide, and attend for $\mathrm{a}^{\prime}$ variable length of time, and then are no more seen.

With the idea of finding out what happens to these patients and when, I have undertaken an enquiry and endeavoured to trace the end of such cases. When I began, I imagined the majority of them would be dead, and accordingly first applied to the various registrars for details, but meeting with somewhat poor results, I next sent reply-paid postcards to the patients themselves, enquiring after their health, and was very agreeably surprised to find the number who were still living.

The types of retinal lesions I selected were flame-shaped hæmorrhages and signs of vascular disease in the retina, venous thrombosis and hæmorrhagic retinitis, "embolism" of the central artery, retinitis circinata; in fact, all those conditions usually associated with the condition of arterio-sclerosis. I purposely omitted true albuminuric retinitis, as the fate of such patients is well-known. A few cases of diabetic retinitis have crept in accidentally and a few traumatic hæmorrhages, but these latter have not been included in the statistics.

In one way or another I have collected 159 cases from the

\footnotetext{
* Read at the Oxford Ophthalmological Congress, July, 1916.
} 
records of the Oxford Eye Hospital and my private records, and have managed to trace 124 of them; of the total number 63 were males, the remainder 96 females -58 of them married and 38 single.

To examine more accurately the prognostic influence of these lesions, I have arranged the cases according to their ages, taking, first, cases under 50 , the majority being between 40 and 50 ; then, cases between 50 and 60 ; then those between 60 and 70 ; next, those between 70 and 80 ; and, lastly, those over 80 .

Considering the first group, cases under 50 years of age. These number 26, and of these 18 are women and 8 men.

One finds a remarkable difference in the length of life in the various cases, and this difference is seen to be due to the presence of albumen in the urine.

For example-of those with albumen present:

Two died after five years, one of cerebral hæmorrhage, the other of phthisis.

One died after three years ten months, of chronic Bright's disease.

One " three " five ", of nephritis.

One alive after two ", three ,"

One died in three months, of granular kidney.

One ", four ,, a syphilitic subject.

One alive after six years, in spite of a blood pressure of $220 \mathrm{~mm}$., but comparing these with those that had no albumen, one finds:-

One living after 28 years. Age 74 .

, , , 25 , Age 40.

$, \quad, \quad, 17 \quad, \quad$ Age 66.

" died " $16, "$ of cerebral thrombosis, pneumonia, and heart failure, at the age of 67 , but he had four strokes.

One living after 15 years. Age 50.

$, \quad, \quad, 11, \quad$ Age 55.

$, \quad, \quad, \quad 4 \quad, \quad$ Age 48.

In many of the cases I, unfortunately, have no note as to the state of the urine; but one has enough evidence, I think, to say quite definitely that in young patients with vascular disease of the retina, the presence or absence of albumen in the urine is by far the most important factor in forming an opinion as to the prognosis re life.

Taking next the cases between 50 and 59 . They number 47, of whom 28 are women and 19 men.

The difference in prognosis between those with and without albumen is not so marked as in the preceding group. Whereas in that group the longest hife I could find with albumen was six years, many in this one have lived a considerable time. I need not weary you with reciting the whole number, but just refer to a few, such as Case No. 64. At the age of 58 had flame-shaped hæmorrhages in the left eye, and some albumen in the urine. She is still alive, age 71 
-13 years after the original lesion. Another lived nine years, dying of syncope, age 63. She had hæmorrhagic retinitis and thickened arteries.

Another case of interest is No. 67-a man who had a vitreous hæmorrhage, arteries enormously thick, blood pressure of 200, and a good deal of albumen in the urine. When I first saw him, eighteen months ago, he was quite broken down, could not manage his business, and was altogether in a most tottery condition. I saw him again a month ago. His vitreous hæmorrhage had practically cleared up; he was altogether better and brighter in himself; and he had had a severe attack of appendicitis, with bad operation, in the meantime.

Of cases without albumen, two died under two years; one of them (No. 46) had a blood pressure of $200 \mathrm{~mm}$. and died of a stroke. Others died at 4, 5, 6, and 12 years respectively. Many of the rest are alive at times varying from $1 \frac{1}{2}$ to 16 years, the latter being a woman who had extensive retinal hæmorrhage at the age of 54, and who is still alive, age 70 ; although she is beaten by Case No. 42, a man with hæmorrhagic retinitis at the age of 54 , but no albumen, who is still alive, age $76 ; 22$ years after the original lesion.

Passing on to those cases developing between 60 and 69, they number 54, and are evenly divided, 27 females and 27 males. As before, cases with albumen compare unfavourably with those without.

Examples of cases with albumen:

One died in four years with cardiac asthma.

One , six months with a stroke.

One living after three and a half years, but in poor health.

One „, two years, age 66 .

One,$\quad$ three and a half years, age 68 .

Comparing these with those known to have had no albumen:

(114) Retinitis circinata R.E. at the age of 67. Retinitis circinata L.E. at the age of 66 and much hæmorrhage. Still alive and well after 10 years. Another died after six years, age 70 .

(80) Had a blood pressure of 250 at the age of 64, with flameshaped hæmorrhages. Died four and a half years later, old hemiplegia and acute bronchitis.

(84) Had hæmorrhages in the left eye followed by glaucoma twenty-five years ago, and is still alive, age 84 .

(85) Another at 65 years, who had venous thrombosis, died of senile decay, aged 81 , sixteen years later.

(91) At 68 years, thickened arteries and ? embolism, died at the age of 78 of cerebral hæmorrhage, about ten years later; and so on.

Thus at this age the prognosis re life of retinal vascular disease 
is, on the whole, extraordinarily good, the normal expectation of life at 60 being roughly $13 \frac{1}{2}$ years, and at 69 nearly 9 years.

Now coming to the cases between 70 and 80 . These number 26 ; 20 females and 6 males. They show the remarkable age to which these patients live.

(129) Age 75, male, with much albumen. Hæmorrhages and thickened arteries, is still alive, age 83 , after 8 years.

Other cases are:-Alive, age 75, after 2 years; 77, after 5 years; died at 83 , after 10 years; died at 79 , after 8 years; alive at 75 , after 5 years.

(136) Alive at 80 , living 8 years and 3 months.

(139) Alive at 80 , after 6 years.

(143) Blood pressure 220, no albumen, died aged 78, of a cerebral hæmorrhage, living $5 \frac{1}{2}$ years.

(145) Hæmorrhage at age of 75, alive at 82, after 7 years.

(149a) Vascular disease and diabetic retinitis, alive after 5 years, age 78 .

One other case I forgot to mention is a man (No. 75) who had both albumen and sugar at the age of 60 , and who lived for 7 years before his death, the actual cause of which I could not discover.

Finally, those 80 years of age and over.

There are 5 of these cases- 3 men and 2 women.

(151) Age 87, with hæmorrhage, died, aged 93, of senile decay. 86.

(152) Age 81, with albumen and hæmorrhage, still alive, aged

(153) Age 86, embolism, died, aged 89, of cerebral hæmorrhage.

(154) Age 80, hæmorrhage and thickened arteries, still alive, aged 84 .

The fifth I cannot trace after seven months, but these few cases bear out the fact, I think, that the older the patient, the less important from the point of view of prognosis to life are the vascular diseases of the retina.

As regards the treatment of these cases, this, of course, is the treatment of their general condition. Rules for their course of life, and instructions as regards diet, are important, with the idea of giving their kidneys as light work as possible; but perhaps the most important is, to avoid all physical strain.

As regards use of the eyes, I should like to hear the opinion of others. Whilst it is common-sense not to work a damaged organ hard, I must confess I have never seen any damage done to these eyes by ordinary use; and as it is a condition which may last more or less to the end of the patient's life, it seems to me a mistake to prohibit the use of the eyes, as is sometimes done, for, after all, what is the use of having eyes if they are never used.

Lastly, as regards causation. Very many are no doubt due to thrombosis of vein or artery, and in some cases it is difficult to 
determine exactlv which vessel is at fault. Some years back, after Sir Almroth Wright's suggestion, that many ocular hæmorrhages might be due to thrombosis, I measured the coagulation-time of the blood, but, as a rule, rarely found much variation from the normal. Nor is this, I think, to be wondered at. The lesion may have occurred a few days to a few months before being seen, and the coagulation-time is known to vary very rapidly with differences in diet, time of day, length of time after meals, etc. The only thing of interest I did come across was the fact that potassium iodide had by far the most powerful action in prolonging the coagulation time of any drug I tried. In my experience, it was much more potent in this respect than citric acid, and in those cases of iodism where the symptoms are almost if not entirely due to this property, they can, to a certain extent, be obviated by giving calcium at the same time, or, what comes to the same thing, giving it in large doses of milk, as one used to be taught some years before anyone took any notice of coagulation-times.

This fact, in addition to its power of lowering the blood pressure, makes the drug of real value in the treatment. Other means of lowering the blood pressure, such as electrical treatment, I have been disappointed in; the effect seems to be only temporary, and blood pressure, after all, is but a symptom, and one that the patient does not object to. One old man, in particular, I remember used to say, "I'm sure my blood pressure is well over 200; I feel so fit and energetic."

Final conclusions from study of statistics.--Retinal lesions are considerably more common in women than men, and that not altogether due to child-bearing, as 38 of the 96 women were, as far as I could discover, unmarried. The cases were most numerous between the ages of 60 and 70, and next between 50 and 60 .

The older the patient, the better the prognosis as regards life, irrespective of the presence of albumen in the urine to a large extent, whilst the younger the patient, the worse the prognosis, especially so if albumen is present in the urine.

Lastly, I wish to thank Dr. A. L. Ormerod, M.O.H. for the City of Oxford, and Dr. E. Morton, M.O.H. for part of the County of Oxford, for their valuable advice and assistance in the tracing of many of the cases. 
166 The British Journal of Ophthalmology.

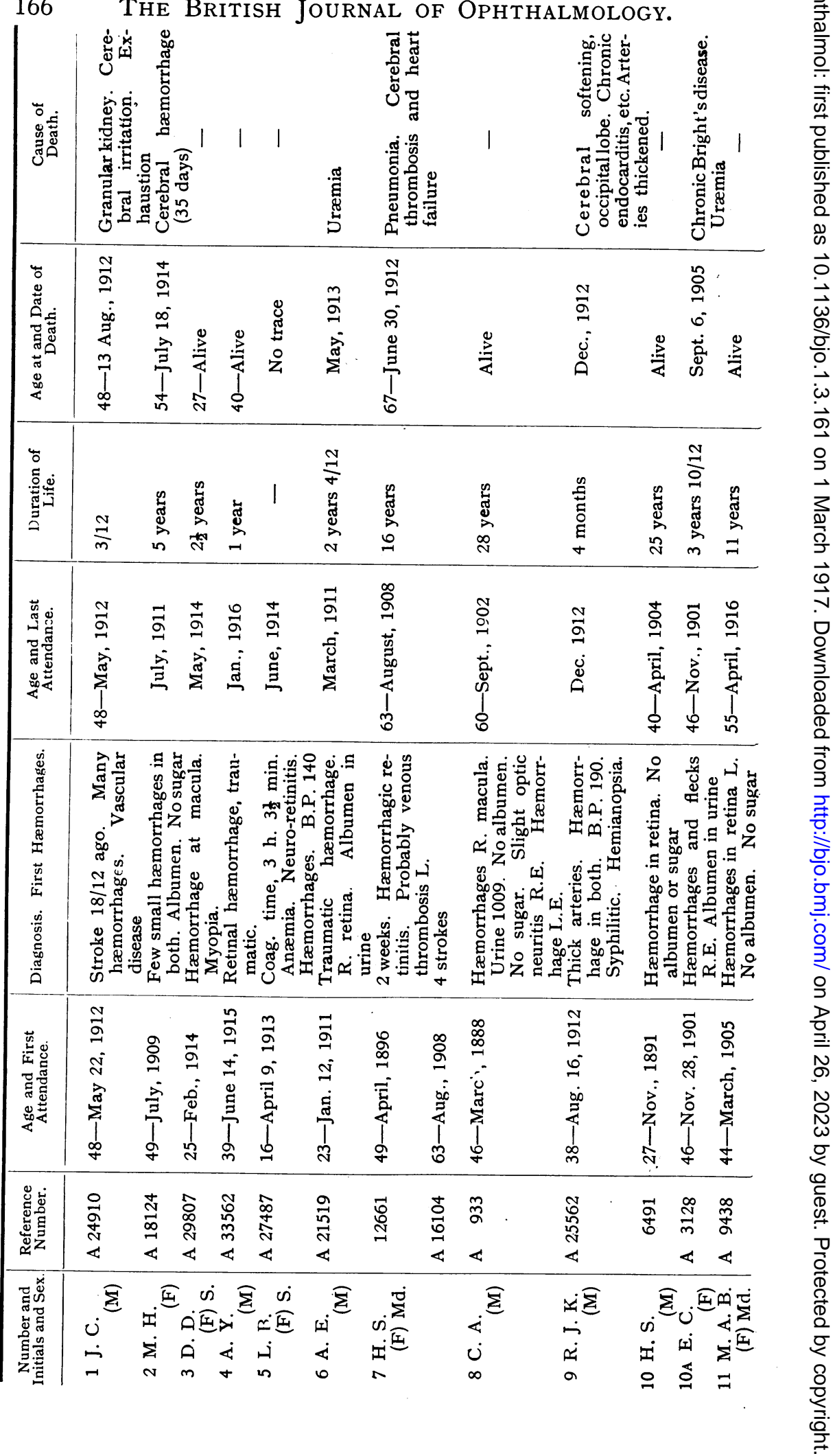


Influence of Retinal Disease on Prognosis of Life. 167

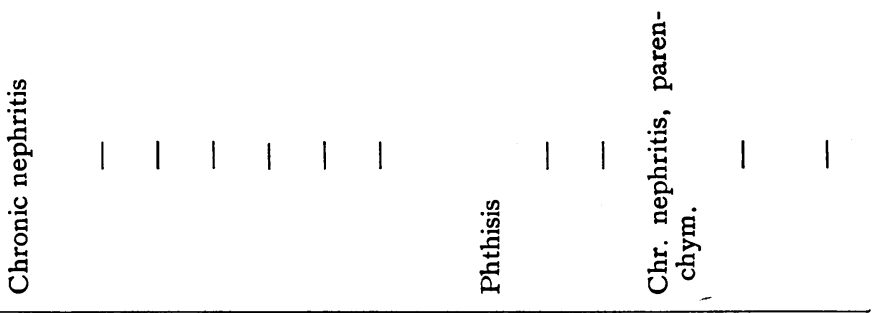

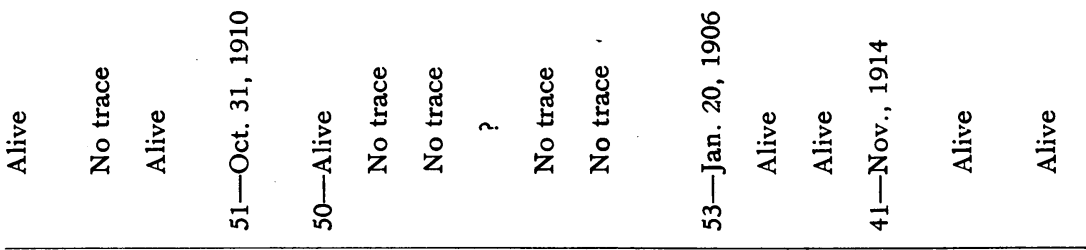

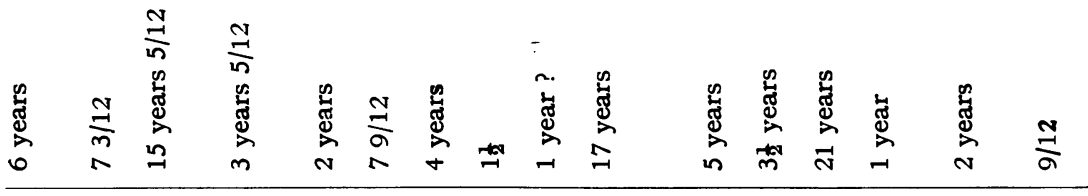

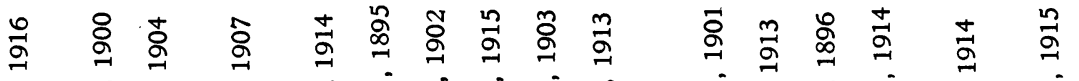

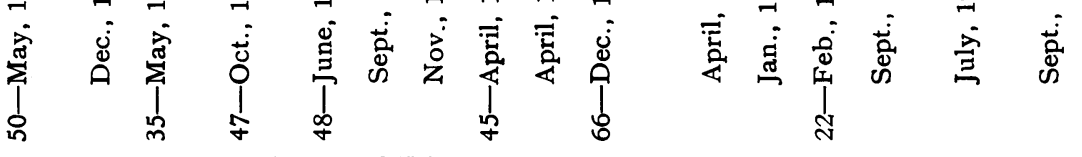

ญ.

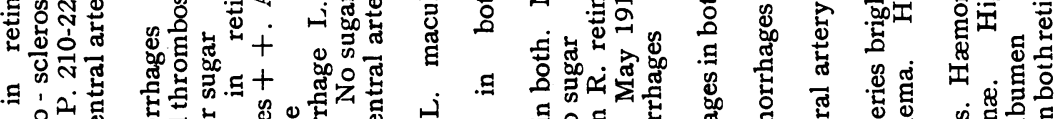

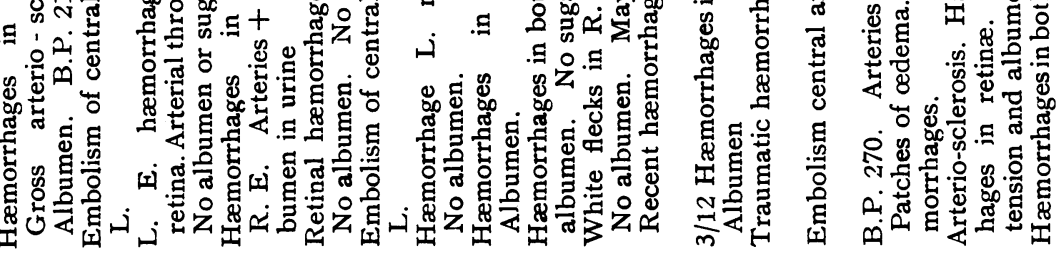

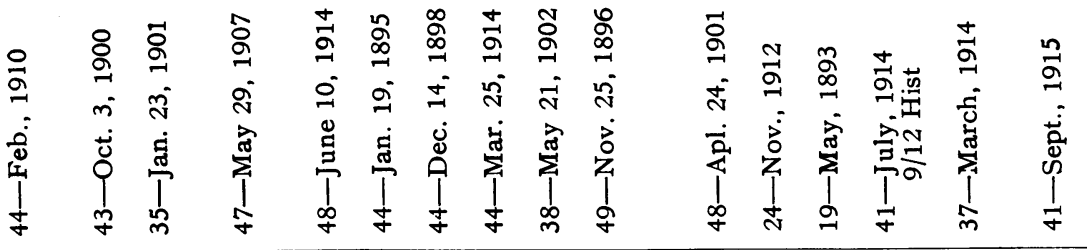

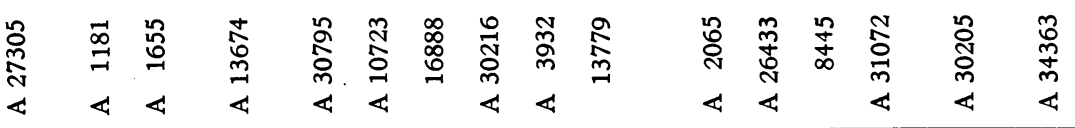

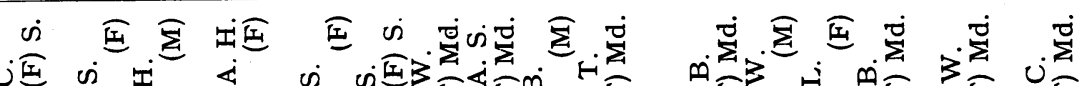

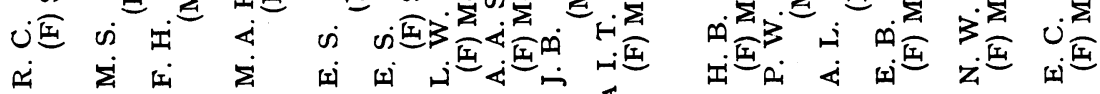

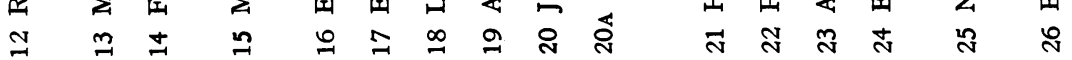


168 The British Journal of Ophthalmology.

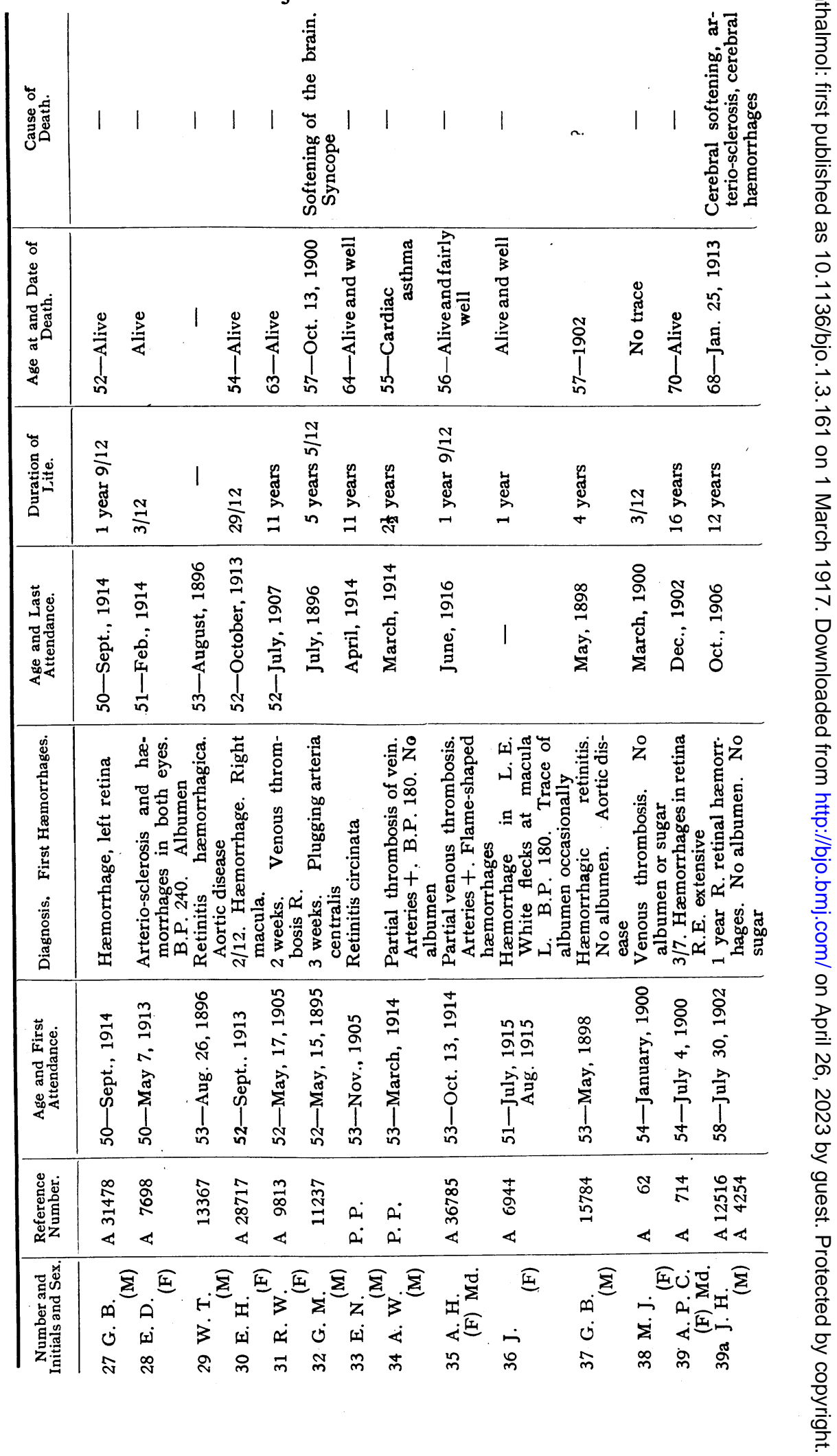


Influence of Retinal Disense on Prognosis of Life. 169
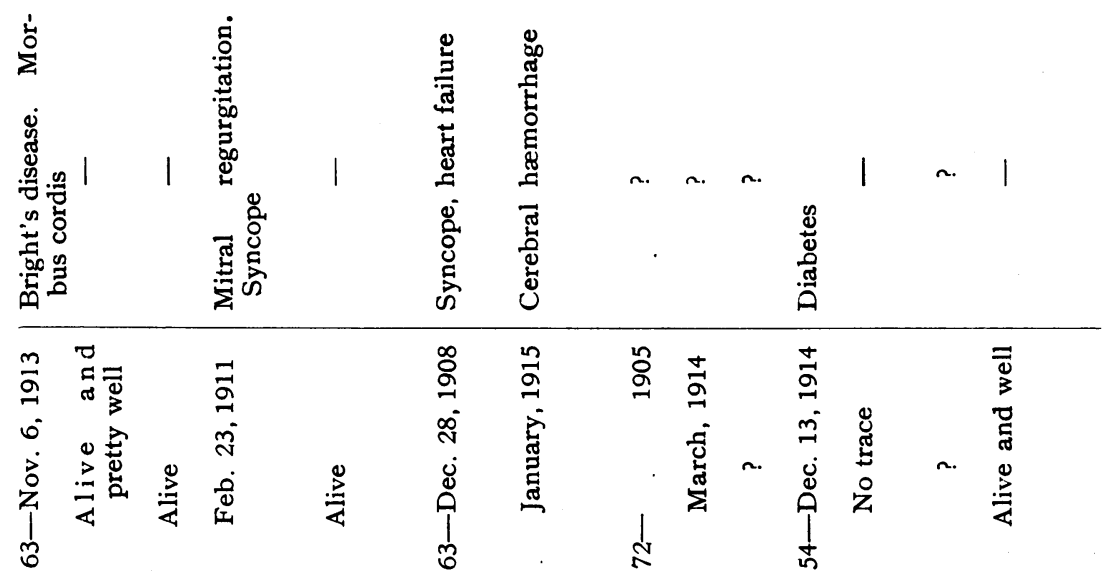

吕
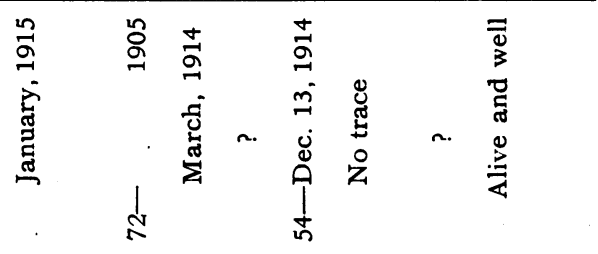

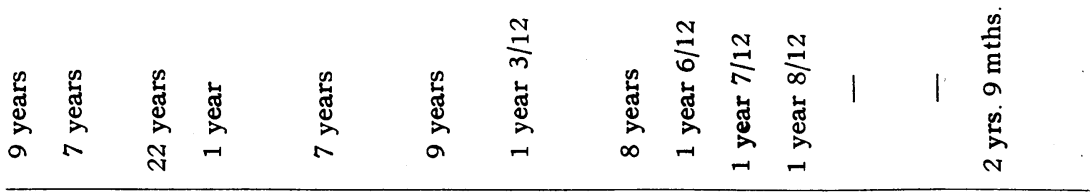

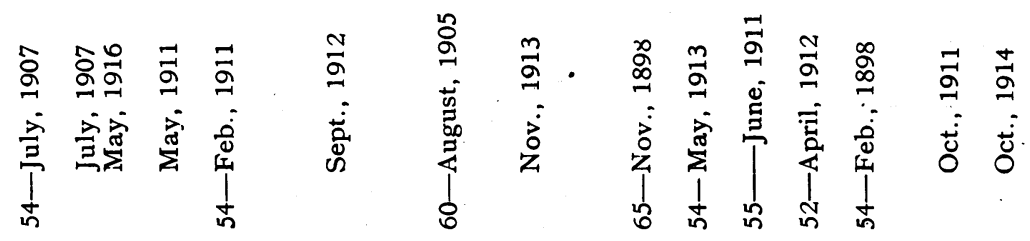

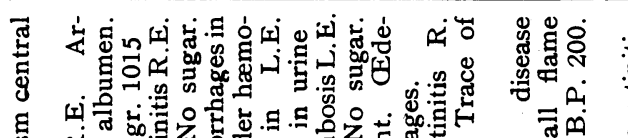
商

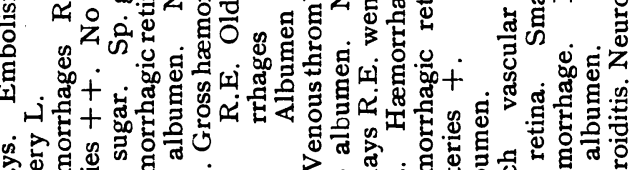

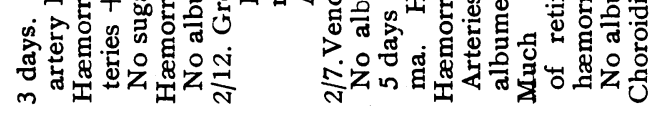

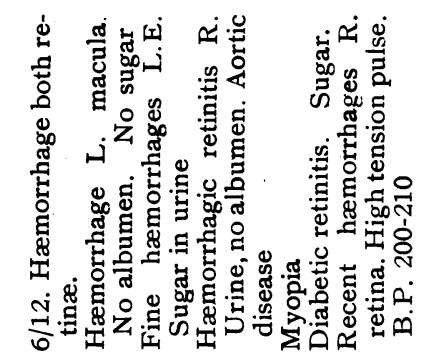

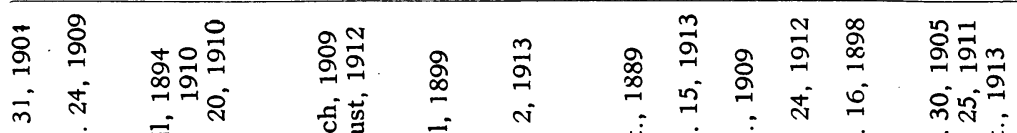

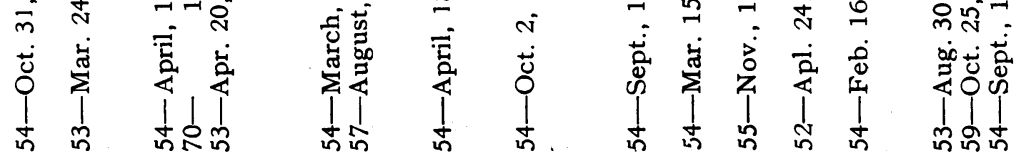

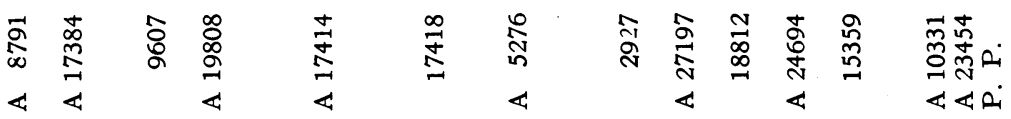

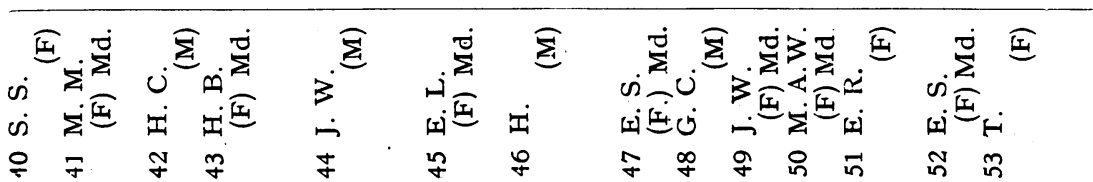


The British Journal of Ophthalmology.

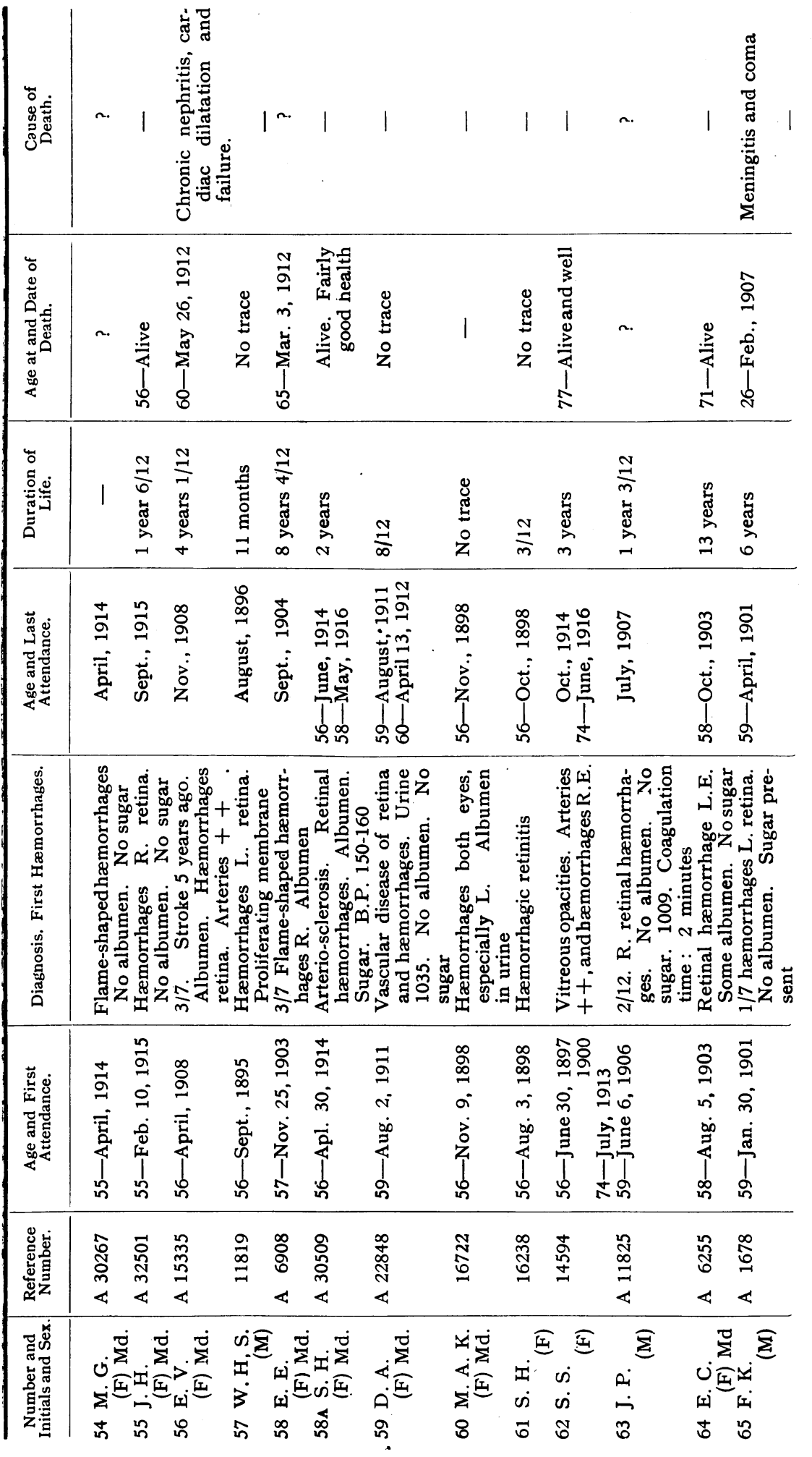


Influence of Retinal Disease on Prognosis of Life. 171
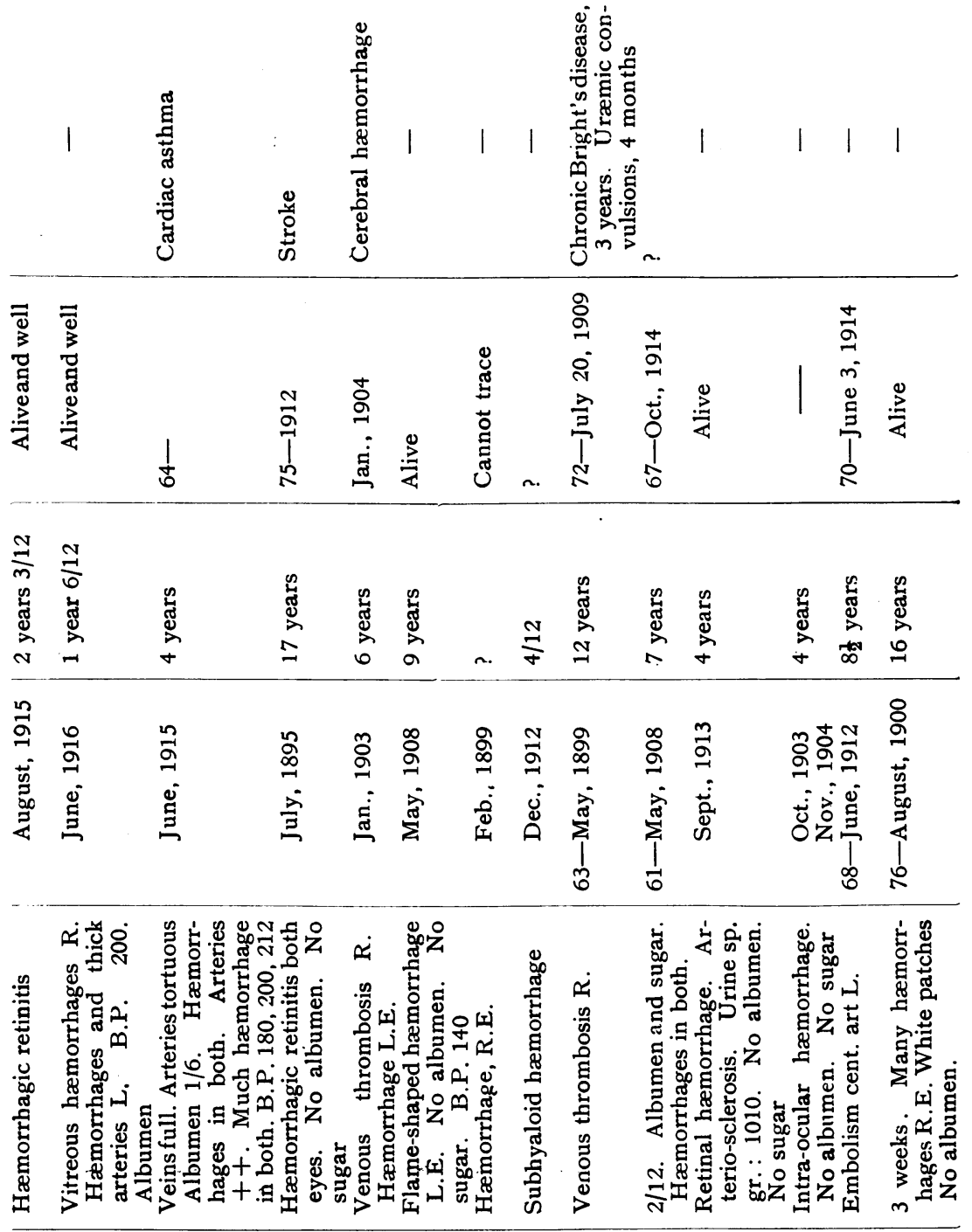

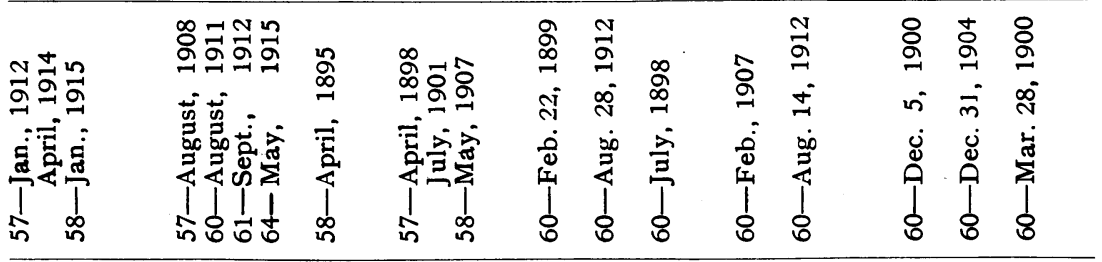

\begin{tabular}{|c|c|c|c|c|c|c|}
\hline 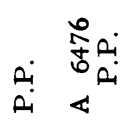 & 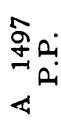 & $\underset{\Xi}{\stackrel{p}{\Xi}}$ & 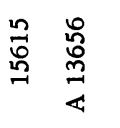 & 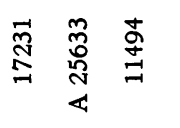 & 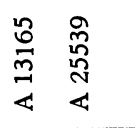 & 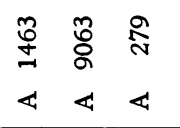 \\
\hline$\underline{\mathrm{I}}_{3} \overline{\mathrm{E}}$ & $\bar{\Xi}$ & $\overline{\mathrm{E}}$ & $\underbrace{}_{0} \underline{\Xi}$ & 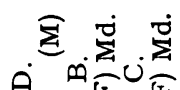 & $\widehat{\Sigma}_{\dot{i}} \overline{\underline{\varepsilon}}$ & 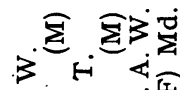 \\
\hline$\infty 3$ & 实 & 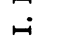 & $\dot{4} \dot{\Sigma}$ & 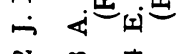 & पi & 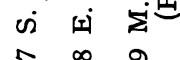 \\
\hline$\therefore \hat{0}$ & 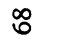 & 8 & $R=$ & $n \pi$ & & \\
\hline
\end{tabular}


172 The British Journal of Ophthalmology.

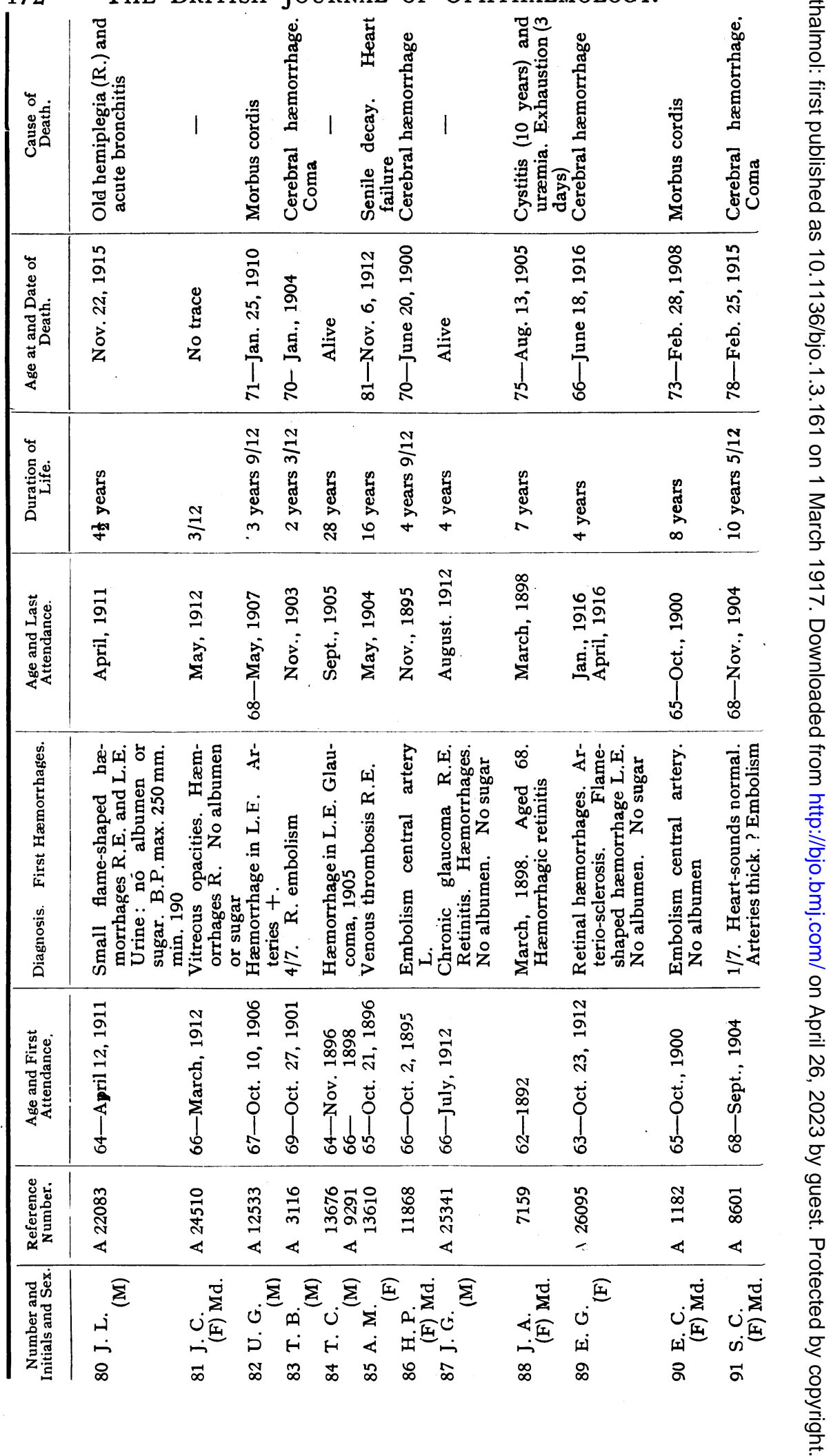


Influence of Retinal Disease on Prognosis of Life. 173

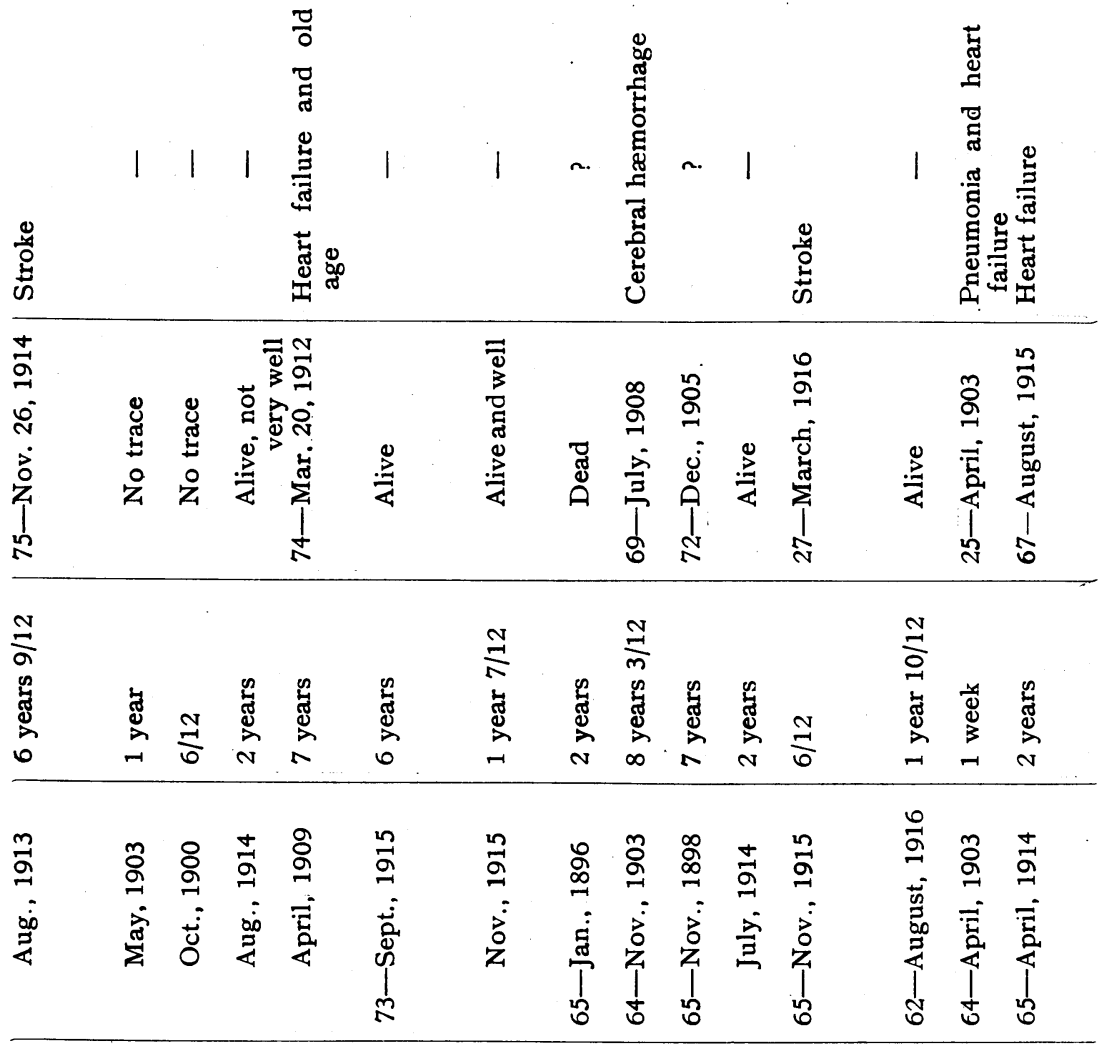

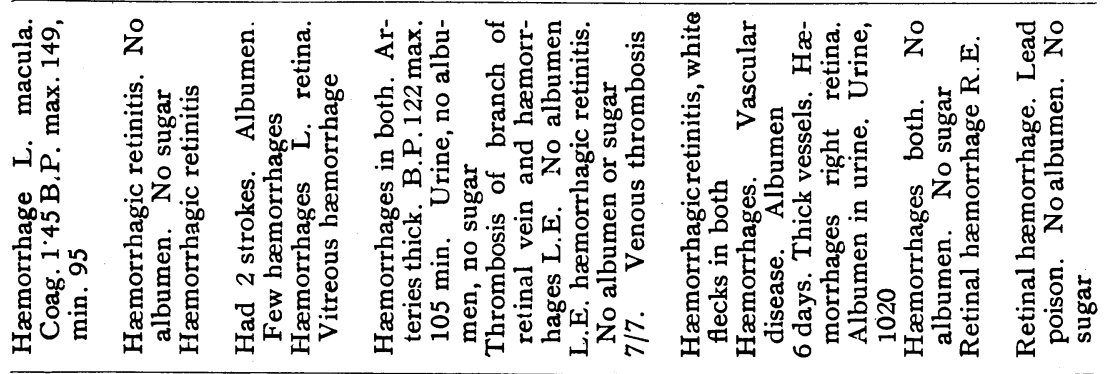

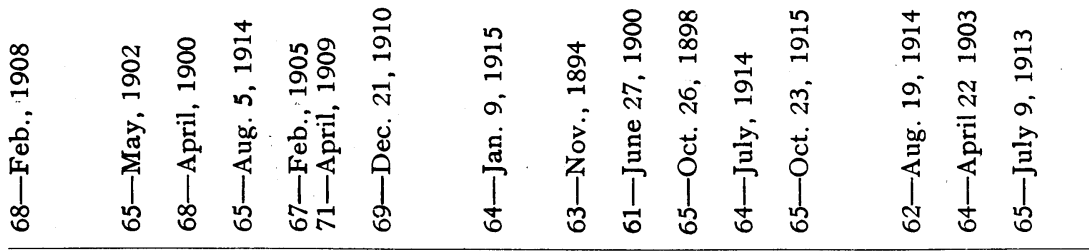

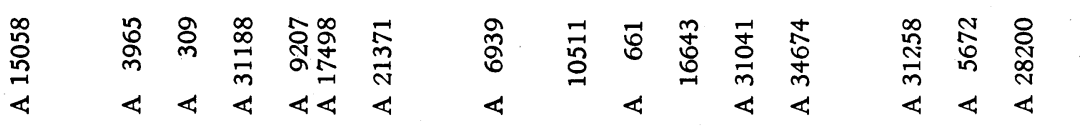

\begin{tabular}{|c|c|c|c|c|}
\hline 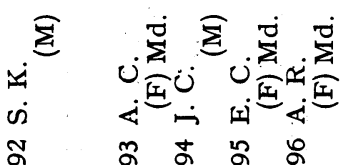 & $\begin{array}{l}\text { 这 } \\
\text { 国 } \\
\text { a }\end{array}$ & 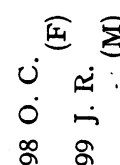 & 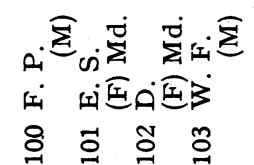 & 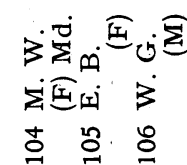 \\
\hline
\end{tabular}


174 The British Journal of Ophthalmology.

\begin{tabular}{|c|c|c|c|c|c|c|c|c|c|c|}
\hline 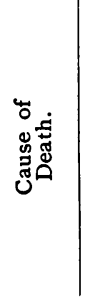 & n. & 1 & 1 & 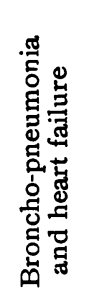 & 1 & 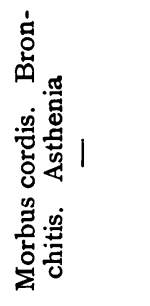 & 1 & 1 & 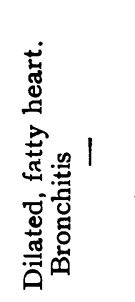 & 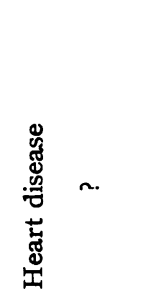 \\
\hline 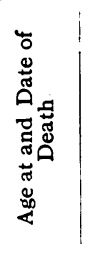 & 妾 & 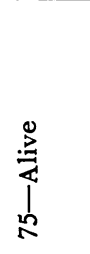 & $\stackrel{ \pm}{a}$ & 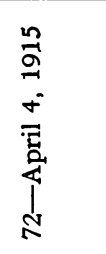 & $\begin{array}{l}\mathscr{\Xi} \\
\stackrel{\Xi}{\Xi} \\
\circ\end{array}$ & 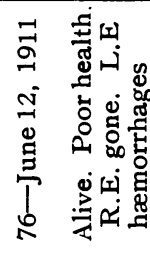 & 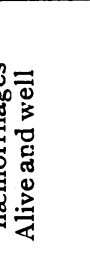 & 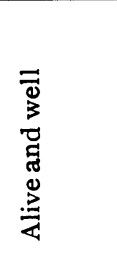 & 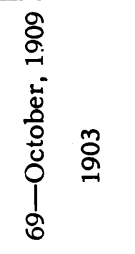 & $\begin{array}{ll}\infty & 8 \\
0 & 0 \\
1 & 1 \\
\frac{1}{1} & 0\end{array}$ \\
\hline 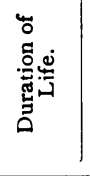 & 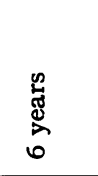 & 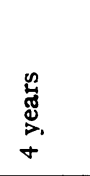 & 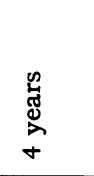 & 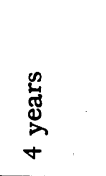 & & 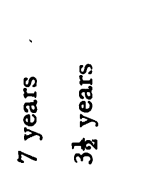 & 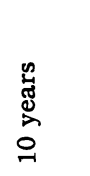 & $\begin{array}{l}\stackrel{n}{d} \\
\stackrel{d}{d} \\
\sim\end{array}$ & 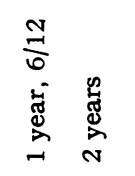 & 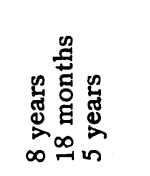 \\
\hline 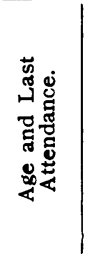 & 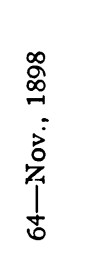 & 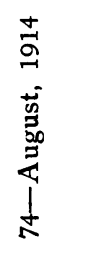 & $\begin{array}{l}\bar{\Xi} \\
\bar{\sigma} \\
\sum_{0}^{\infty} \\
0\end{array}$ & 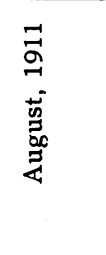 & & 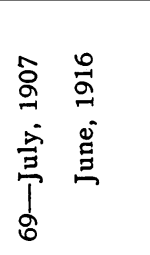 & $\begin{array}{l}\stackrel{0}{a} \\
a \\
\Xi \\
\Xi\end{array}$ & $\begin{array}{l}\stackrel{0}{a} \\
a \\
\Xi \\
\Xi\end{array}$ & 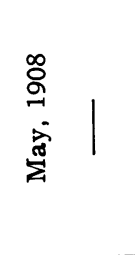 & 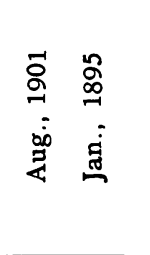 \\
\hline 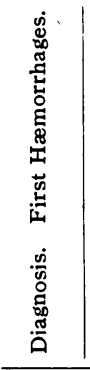 & 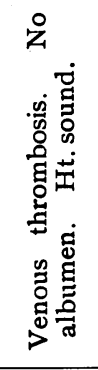 & 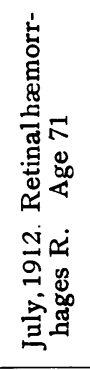 & 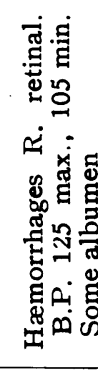 & 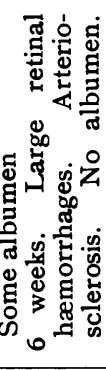 & 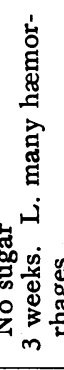 & 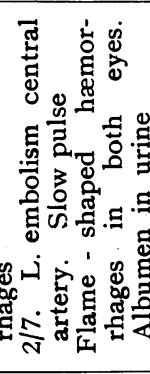 & 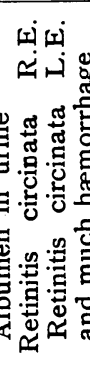 & 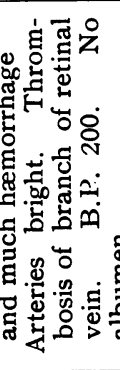 & 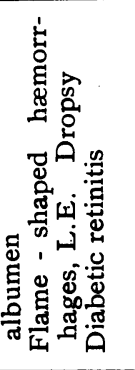 & 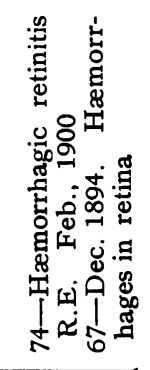 \\
\hline 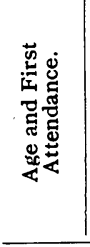 & $\begin{array}{l}\infty \\
0 \\
0 \\
-1 \\
0 \\
\dot{0} \\
0 \\
1 \\
1 \\
1 \\
0\end{array}$ & $\begin{array}{l}\text { no } \\
\vdots \\
0 \\
\infty \\
\dot{0} \\
0 \\
01 \\
1 \\
0 \\
0\end{array}$ & $\begin{array}{l}\circ \\
\stackrel{2}{0} \\
\dot{\dot{0}} \\
1 \\
1 \\
0\end{array}$ & $\begin{array}{l}\bar{a} \\
a \\
a \\
0 \\
5 \\
1 \\
0\end{array}$ & 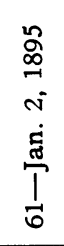 & 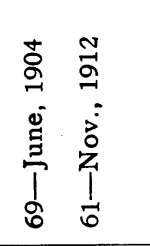 & 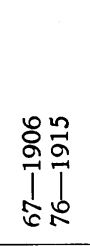 & 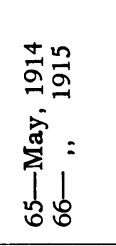 & 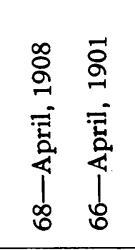 & 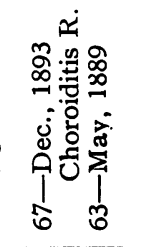 \\
\hline 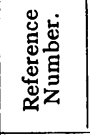 & 㥐 & 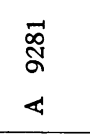 & 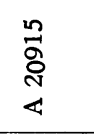 & 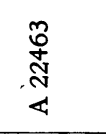 & 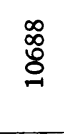 & 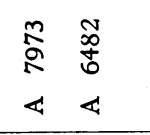 & 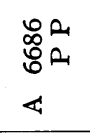 & $\begin{array}{l}\text { N } \\
\text { 令 } \\
4\end{array}$ & 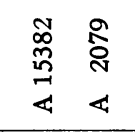 & 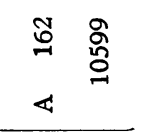 \\
\hline 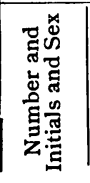 & $\begin{array}{l}\stackrel{\hat{\varepsilon}}{\dot{\varepsilon}} \\
\dot{\sim} \\
\dot{0}\end{array}$ & 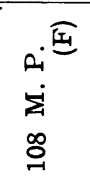 & $\begin{array}{l}\hat{\Sigma} \\
\dot{\underline{\varepsilon}} \\
\dot{0}\end{array}$ & $\begin{array}{l}\bar{E} \\
\dot{B} \\
\dot{0}\end{array}$ & $\begin{array}{l}\dot{E} \\
\dot{0} \\
\Xi\end{array}$ & 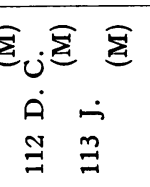 & 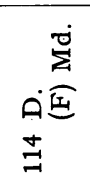 & 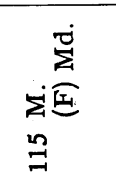 & 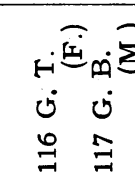 & 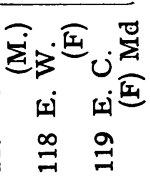 \\
\hline
\end{tabular}


Influence of Retinal. Disease on Prognosis of Life. 175

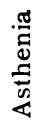

$\cdots \cdots$

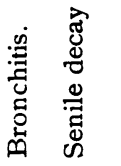

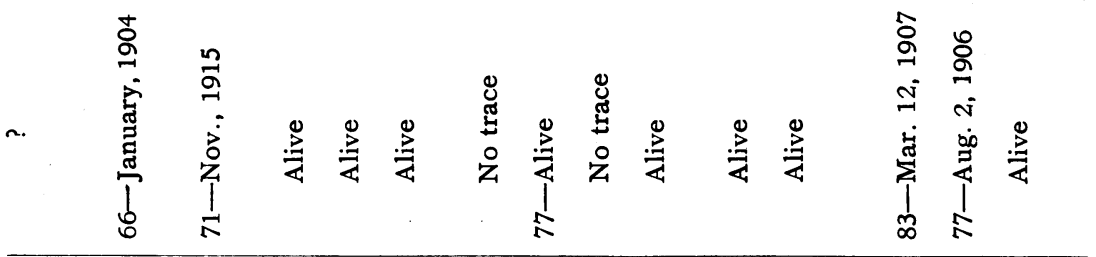

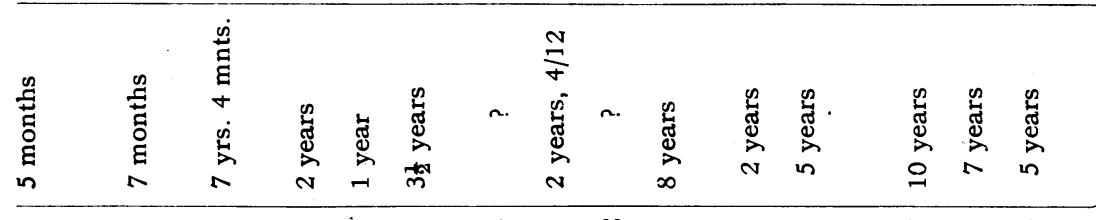

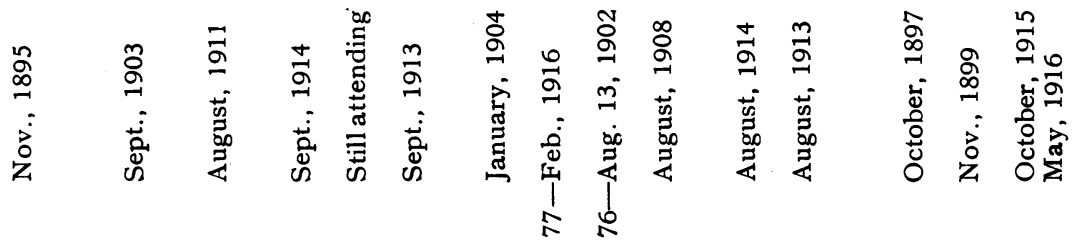

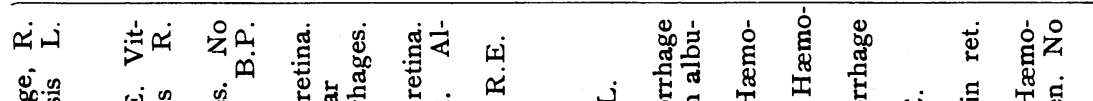

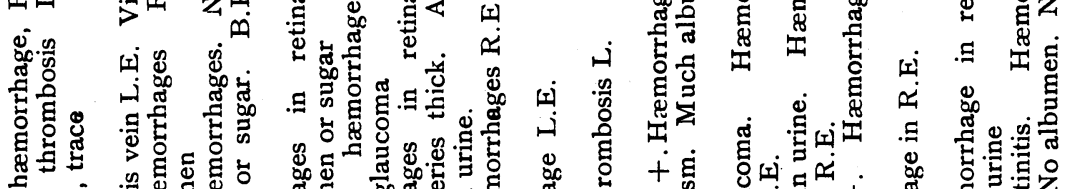

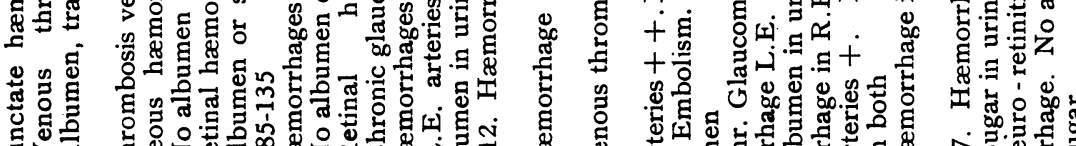

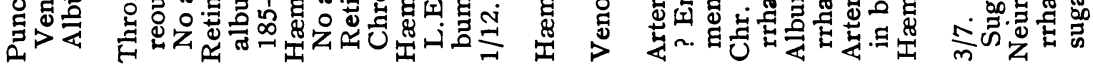

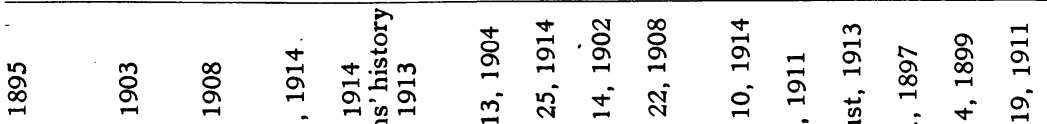

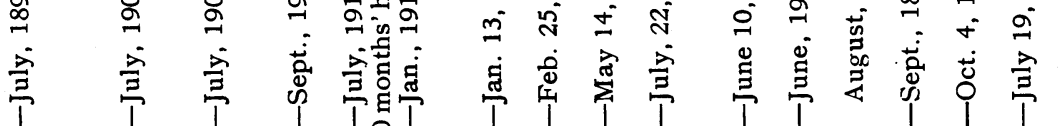

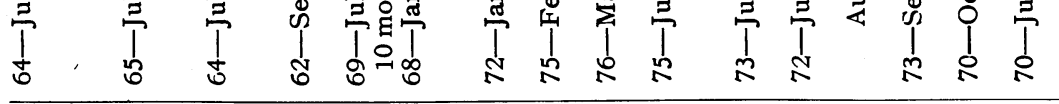

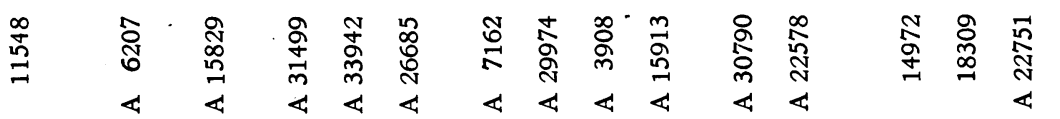

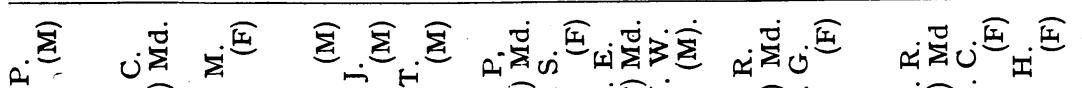

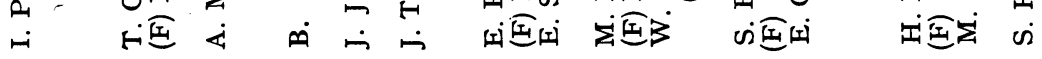

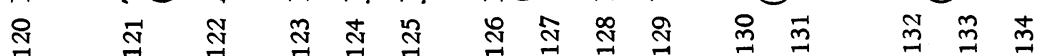




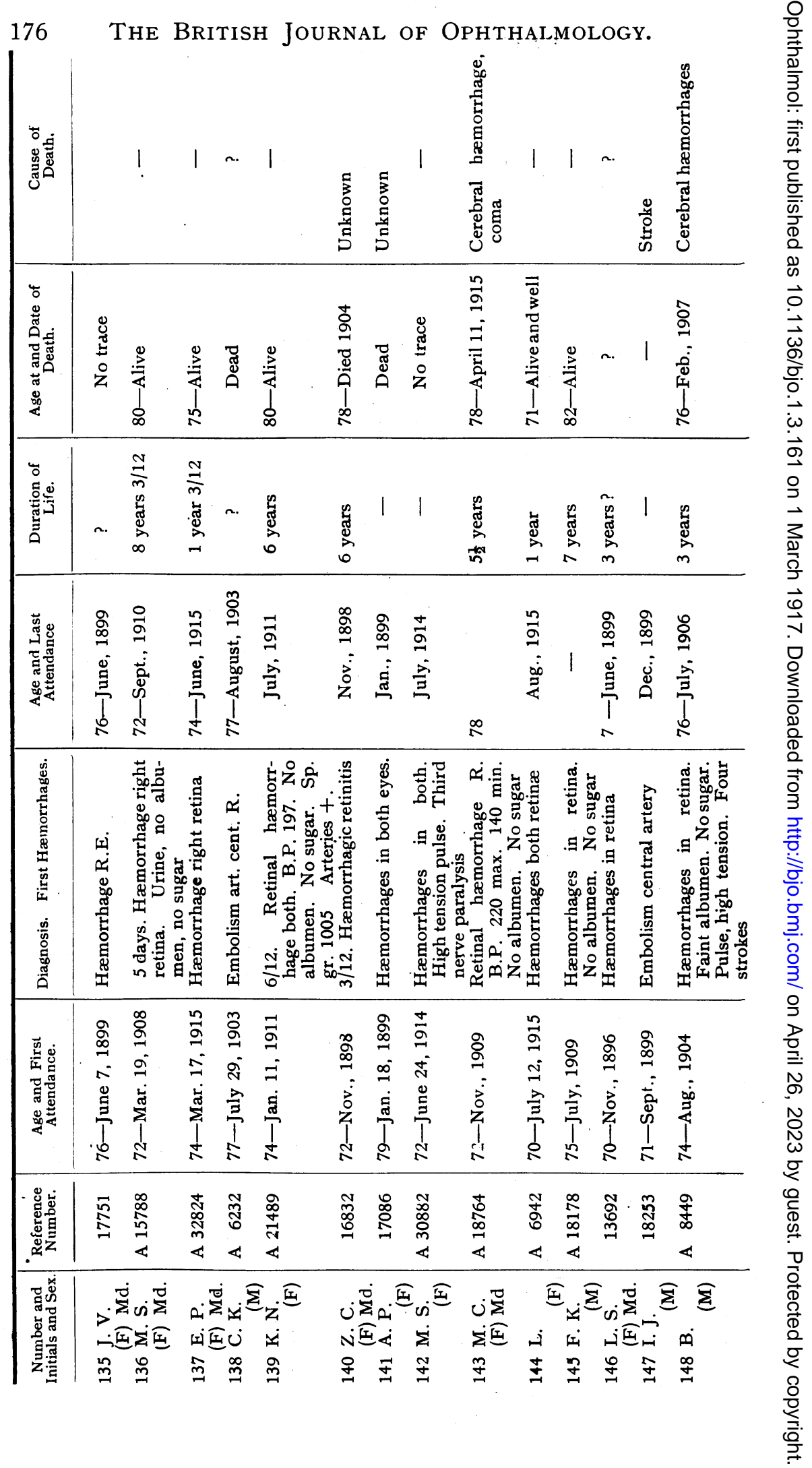


Influence of Retinal Disease on Prognosis of Life. 177

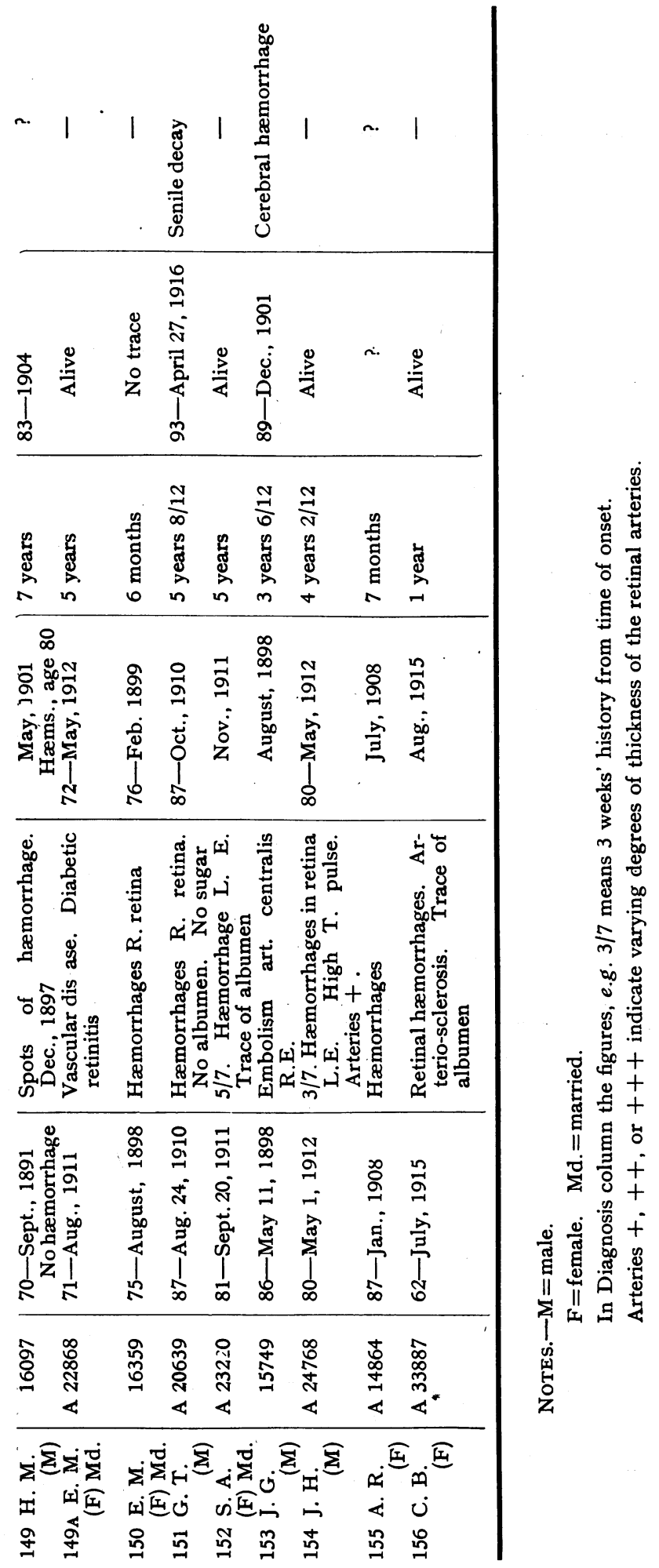

